\title{
Effect of Rare-earth Salts on Corrosion Resistance of Phytic Acid Based Conversion Coatings on Q235 Steel
}

\author{
Yong $\mathrm{Lu}^{1,2}$, Huixia Feng ${ }^{1, *}$ \\ ${ }^{1}$ School of Petrochemical Engineering, Lanzhou University of Technology, Gansu China \\ ${ }^{2}$ Research Institute of Lanzhou Petrochemical Corporation of Petrochina, Gansu China \\ *E-mail: fenghx66@163.com
}

doi: $10.20964 / 2020.08 .84$

Received: 18 March 2020/ Accepted: 8 May 2020 / Published: 10 July 2020

Synergistic effect of rare earth salts conversion coating with phytic acid conversion coating was studied. Rare-earth salts were used as post-treatment to modify the phytic acid coated steel. The corrosion resistance properties of different coatings was investigated with electrochemical impedance spectroscopy in $3.5 \mathrm{wt} . \% \mathrm{NaCl}$ solution. The corrosion resistance of phytic acid coated steel on steel was further enhanced with cerium nitrate post-treatment. The corrosion rate of phytic acid coated steel was seriously impaired by cerium nitrate post-treatment. But scanning electron microscopy (SEM) images indicated that there are also some micro-cracks on the coating surface when phytic acid coated steel was post-treated with cerium nitrate conversion bath. X-ray photoelectron spectroscopy (XPS) results demonstrated that the phytic acid could bind to the steel surface through the formation of -P-O$\mathrm{Fe}$ and the cerium salts on the steel surface existed in the forms of both $\mathrm{Ce}^{3+}$ and $\mathrm{Ce}^{4+}$.

Keywords: conversion coating, phytic acid, rare-earth salts, corrosion

\section{FULL TEXT}

(C) 2020 The Authors. Published by ESG (www.electrochemsci.org). This article is an open access article distributed under the terms and conditions of the Creative Commons Attribution license (http://creativecommons.org/licenses/by/4.0/). 